\title{
Working in a bubble: How can businesses reopen while limiting the risk of COVID-19 outbreaks?
}

\author{
Jeffrey Shaw MD MSc, Troy Day PhD, Nadia Malik BEng MBA, Nancy Barber BA, Hayley Wickenheiser MSc, \\ David N. Fisman MD MPH, Isaac Bogoch MD MSc, John S. Brownstein PhD, Tyler Williamson PhD
}

Cite as: CMAJ 2020 November 2;192:E1362-6. doi: 10.1503/cmaj.201582; early-released September 30, 2020

CMAJ Podcasts: author interview at https://www.cmaj.ca/lookup/doi/10.1503/cmaj.201582/tab-related-content

$\mathbf{T}$ he coronavirus disease 2019 (COVID-19) pandemic has required governments around the world to institute severe physical-distancing measures to reduce the spread of the virus in order to protect public health and ensure health care system capacity. Mitigation measures in many countries, including Canada, have incorporated the temporary closure of nonessential businesses, which has led to bleak employment and economic outlooks. ${ }^{1}$ Essential businesses that were allowed to remain open have, in many cases, led to the ongoing spread of the pandemic. Factories with employees working in close proximity have been particularly affected, not only putting the health and safety of the workforce at risk, but also negatively affecting supply chains and downstream businesses. ${ }^{2} \mathrm{~A}$ trade-off exists between protecting populations from direct effects of severe acute respiratory syndrome coronavirus 2 (SARS-CoV-2) infection and the indirect yet real potential health effects of constraining business and economic activity. ${ }^{3}$

As Canadian jurisdictions relax public health measures and allow nonessential businesses to reopen, 2 main challenges arise: to keep employees safe and to maintain profitable operations given the continued limitations imposed by public health authorities. Measures to prevent SARS-CoV-2 from infiltrating a workforce and a plan for rapid containment of potential cases to mitigate spread within a workforce, should infiltration occur, are essential components of any back-to-work strategy. We analyze strategies that have been proposed for protecting employees during relaxation of public health measures and for limiting the risk of company-wide outbreaks. We also discuss an approach that involves cohorting employees in time, space or both, with associated rules designed to prevent and quickly contain the spread of SARS-CoV-2 in workplaces. We illustrate the approach using an example of a Canadian company, Bombardier, which operates 7 factories across 2 countries and 4 provinces and states, and employs 25000 individuals (10000 in Canada).

\section{KEY POINTS}

- A trade-off exists between protecting populations from direct effects of severe acute respiratory syndrome coronavirus 2 (SARS-CoV-2) infection and the indirect yet real potential health effects of constraining business and economic activity.

- Some businesses, including essential services, have been afflicted by large, company-wide outbreaks that have had serious consequences on the workforce and surrounding community.

- Employers have a responsibility to provide a safe work environment for their employees.

- Creating company cohorts can effectively reduce the risk of company-wide outbreaks; this approach has been implemented successfully at a large Canadian corporation.

\section{Spread of SARS-CoV-2 in workplaces: What's the scale of the problem?}

A substantial proportion of the spread of SARS-CoV-2 has been driven by workplace contacts. ${ }^{4}$ For example, in Alberta, as of May 11, 2020, there were 6183 total cases, with 5539 outside of long-term care. ${ }^{5}$ Of these cases, published news reports ${ }^{6}$ suggest that 1783 (32.1\% of noninstitutional cases) were from an occupational-related exposure. When wider community spread from those outbreaks is included, the number is closer to $50 \%$ of all cases. The Cargill meat plant in the Calgary zone has been called the worst outbreak in Canada and was directly responsible for 941 cases and indirectly responsible for 600 more in the surrounding community. Similar observations have been made in 6 Asian countries, where an estimated $15 \%$ of 690 local transmissions were occupation related. ${ }^{7}$ The "Office Building X" outbreak in South Korea required the isolation of more than 1200 workers in an office tower after $44 \%$ of employees in a call centre within the tower acquired the virus. ${ }^{8}$ These outbreaks represent major 
health concerns and disruption to business operations. In each of these examples, lack of employee physical distancing and failure of early containment have been identified as important contributing factors. Although employers have a responsibility to provide a safe work environment for their employees, implementing physical distancing and rapid containment measures can be challenging or even impossible for many organizations in many business sectors.

Bombardier Aviation was faced with operating in the 2 most affected communities in the country, Montréal and Toronto. Despite carefully following public health recommendations at the time, Bombardier Aviation identified its first case of COVID-19 in March at one of its Global aircraft manufacturing plants, where 900 staff are employed; this required it to cease operations immediately. The plant was closed for 3 consecutive days so that the facility could be thoroughly disinfected, and potentially infected employees could be traced and contacted; those who were in close proximity were required to isolate for 2 weeks. Anyone who had been in contact with the confirmed case and had travelled to another facility was also traced and the appropriate measures taken to disinfect specific areas or require individuals to self-isolate. Because aircraft manufacturing is a long lead-time business and substantial investment is required to carry inventory, reducing manufacturing cycle time is critical. This is typically done by having many employees work dense shifts, which makes physical distancing challenging. Hundreds of employees typically enter or exit a building in a narrow time interval; they must all use elevators, shared locker rooms, restroom facilities and cafeteria services. Of relevance for aircraft manufacturing is the requirement for employees to work in close physical proximity when building an aircraft interior, such as a confined, narrow fuselage, where the $2 \mathrm{~m}$ distance cannot always be respected and where air circulation is not optimal. Such conditions promote the spread of SARS-CoV-2.

The pandemic has shown that similar working conditions exist in various sectors, including manufacturing and food processing, many of which have seen troubling outbreaks. However, the requirement that employees work in close proximity for extended periods of time is not exclusively a problem for big business. Many small businesses require employees to work in similar conditions.

\section{What can be done to limit the spread of SARS- CoV-2 in workplaces?}

If cohorts are designed according to the principles of redundancy and functional working units, both the safety of employees and the resiliency of businesses can be optimized.

\section{Physical distancing through work bubbles}

It is widely accepted that physical distancing measures have substantially reduced the spread of SARS-CoV-2. ${ }^{9-11}$ For many people, physical distancing has largely been achieved through working from home whenever possible. However, for people whose jobs require them to be present in the workplace, complete physical distancing may not always be possible, as groups of employees may need to use shared spaces or be in close physical proximity. One way to balance physical distancing and the need to be at the workplace is for an employer to structure its workforce into cohorts, such that employees within a cohort interact with one another but interactions between cohorts are essentially nonexistent. This approach is analogous to the "social bubbles" that many have adopted, and may be thought of as "work bubbles." Depending upon the logistical constraints of a given business, such work bubbles might be created in a variety of ways, either through physical separation within a workspace or temporal separation via a rotating work schedule, or both.

This kind of workforce structuring provides several benefits, both in terms of public health and in terms of employee and employer safety and well-being (Table 1). Figure 1 presents the basic reproduction number as a function of the effectiveness of physical distancing under 3 different scenarios. The black line presents the shutdown that happened during April and May, with only essential services operating. The solid green line represents the scenario in which all employees return to work for 3 days a week without further mitigation strategies. The dashed blue line represents the scenario in which all employees return to work for 3 days a week, but with 2 temporally separated work bubbles that work on alternating days. It is clear that having 2 temporally separated work bubbles can reduce person-to-person transmission in the community. In addition, if the cohorts are fully separated, it simultaneously reduces the risk of full business closure in the event that an employee tests positive.

At Bombardier, office staff (e.g., engineering, finance, management, programs) who could work from home and meet all their deliverables were obligated to do so. This strategy allowed only employees related to aircraft build and aircraft deliveries to be physically on site. For such workers, the company's manufacturing work methodology for unionized employees was already based on cohorts - i.e., time-based shifts - and Bombardier implemented an additional combination of physical and temporal work bubbles based on the following principles: ${ }^{1}$

- Functional work bubbles should have the lowest number of individuals who are required to accomplish the work. ${ }^{2}$

- Work bubbles should be designed such that business operations may continue even with the removal of any 1 bubble from the workforce. ${ }^{3}$

- Work bubbles should be strictly separated in time or space or both, effectively eliminating the risk of transmission between work bubbles. This can be accomplished by rotating workdays or by physical distancing, with meticulous decontamination of shared spaces after use by 1 work bubble. $^{4}$

- Moving individuals between work bubbles should ideally be accomplished with a 5-day gap between cluster exposures, to match the incubation time of the virus.

Bombardier further enabled physical distancing by staggering employees' workplace entry and departure times - effectively eliminating the overlap between different cohorts arriving at and leaving the facility - as well as their access to common areas 
Table 1: Benefits and challenges of implementing work bubbles during the COVID-19 pandemic

Public health

Benefits

- It can reduce the reproduction number of the disease (Figure 1).

- It can increase the efficiency and effectiveness of track-and-trace systems by providing a tool for immediate removal of at-risk individuals from their employment community.

- It is a pre-emptive approach to employee contact tracing that reduces spread not only within a company, but also in the surrounding community by providing a tool for early contact isolation.

Challenges

- It is difficult to enforce.

Employees

Benefits

- It is an additional way to protect employees against acquiring COVID-19 in the workplace.

- It can increase employee confidence in the safety of the workplace.

Challenges

- It may negatively affect the work schedule.

- Employees may not be able to interact socially with those outside their work bubble.

- There may be decreased productivity.

Employers

Benefits

- If employment bubbles within a business are modular and redundant, specific bubbles can be shut down without disruption to the ongoing business operation as a whole.

- It allows employers to ensure that they are taking active preventive measures to keep their employees safe.

Challenges

- It introduces administrative complexity in workforce scheduling.

- It may be difficult to ensure separation of work bubbles from one another.

Note: COVID-19 = coronavirus disease 2019.

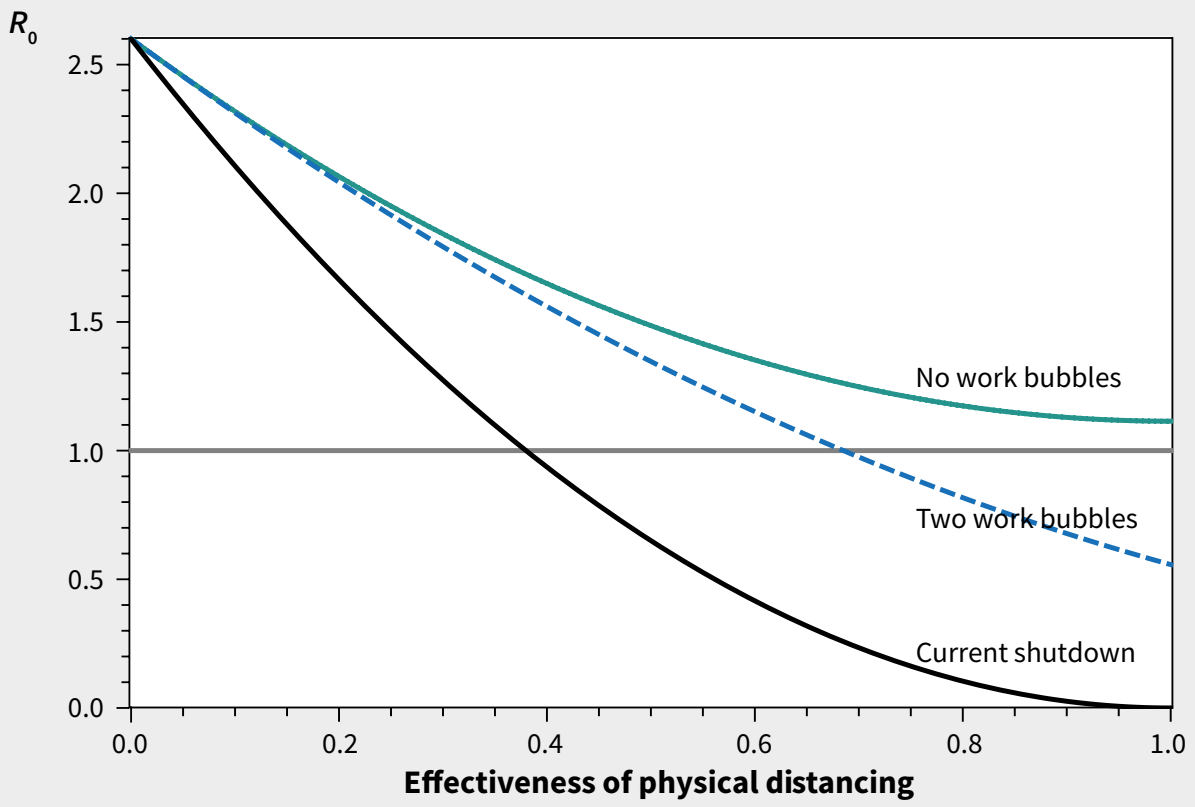

Figure 1: Basic reproduction number as a function of the effectiveness of physical distancing under 3 scenarios: current shutdown with only essential services operating (black line), all employees return to work for 3 days a week without further mitigation strategies (solid green line), and all employees return to work for 3 days a week but with 2 temporally separated work bubbles that work on alternating days (dashed blue line). See methodology in Appendix 1 (available at www.cmaj.ca/lookup/doi/10.1503/cmaj.201582/ tab-related-content). 
such as locker rooms and cafeterias. Reinforcement and changes to the cohort-based strategy resulted in successful discussions with unions, as shift times were altered to limit the on-site population during any given shift. Similarly, Bombardier made the decision that cohorts would not freely move between different sites but be localized to a single site, to further minimize employee interactions. Specifically, Bombardier increased its weekday time-based cohorts (day, evening, night) from 8-hour to 10-hour shifts. The weekend remained a 12-hour shift, as it already represented a small population of employees and was an established cohort. Modifications to the time-based cohorts allowed the company to effectively manage the number of employees in common areas, owing to the overall number of employees on site, and allowed for disinfection of common areas several times throughout the day as well as between shifts; it also allowed for business operations to continue in the event that an employee tested positive for SARS-CoV-2, as exposure would be limited to their particular cohort.

To further protect employees and reduce potential spread, a pre-existing "cohort of a cohort" was also enforced. Now, employees are dedicated to working on specific aircraft without access to another aircraft or a different cohort of employees. Although this was key with respect to safety, it continues to pose challenges to the organization, as employees have different skill sets and expertise that are often needed at the same time in different cohorts.

Rapid identification and isolation of symptomatic cases Another pillar of the public health approach to COVID-19 has been early identification and isolation of cases. This strategy has been successful at limiting the spread of disease in Australia, South Korea and Hong Kong by thorough and rapid contact tracing. ${ }^{12-14}$ However, the general success of this strategy is directly related to the speed at which individuals with positive symptoms self-isolate, the availability of testing and the capacity of the system for contact tracing. ${ }^{12,14}$

When considered in connection with a work bubble strategy, a daily symptom screen is widely regarded as another way to reduce the probability of an employment force outbreak. ${ }^{15}$ For example, Alberta Health Services has mandated that all health care workers complete an electronic self-report screening instrument before entering the workplace. ${ }^{15}$ Employees experiencing any COVID-like symptoms (fever, cough, etc.) are instructed to stay home, not attend the workplace and, as directed by local public health authorities, seek testing. As testing is administered by provincial governments in Canada, strategies for rapid testing are largely outside of the control of employers. However, governments should make every effort possible to ensure rapid testing for symptomatic individuals and individuals who may have had contact with a person who has COVID-19. The testing of asymptomatic individuals is available in some jurisdictions and allows for even earlier detection and prevention of COVID-19, but is not generally recommended. ${ }^{16}$

If work bubbles are carefully managed, an employee who tests positive for SARS-CoV-2 can notify their employer, and their work bubble can be instructed to self-isolate efficiently. This rapid isolation strategy has a benefit to both public health, enabling efficient workplace contact tracing, and to the employer, restricting the exposure to those in the same work bubble, thereby potentially containing the outbreak.

\section{Conclusion}

As we begin to gradually relax the public health measures that have been implemented to slow the spread of COVID-19 in Canada, it is essential to consider how to limit the risk of the disease in the workplace. Implementing a work bubble strategy that physically separates employees either spatially or temporally (or both) through adjusted work schedules will reduce the risk of company-wide disease transmission and reduce the risk of full operational shutdown. Practical challenges to implementing these strategies exist, as Bombardier's experience has shown, but with careful planning and technological assistance, the risks of returning to the workplace can be reduced.

\section{References}

1. Business Outlook Survey - Spring 2020. Ottawa: Bank of Canada. 2020; 2020 Apr. 6. Available: www.bankofcanada.ca/2020/04/business-outlook-survey -spring-2020/ (accessed 2020 Sept. 10).

2. Ivanov D. The impacts of epidemic outbreaks on global supply chains: a simulation-based analysis on the coronavirus outbreak (COVID-19/SARSCoV-2) case. Transp Res E Logist Trans Rev 2020 Apr;136:101922. doi: 10.1016/j. tre.2020.101922.

3. Glover A, Heathcote J, Krueger D, et al. Health versus wealth: on the distributional effects of controlling a pandemic. NBER working paper no. 27046. Cambridge (MA): The National Bureau of Economic Research; 2020.

4. Koh D. Occupational risk for COVID-19 infection [editorial]. Occup Med (Lond) 2020;70:3-5.

5. Chief medical officer of health COVID-19 update - May 11, 2020: Alberta's chief medical officer of health provides an update on COVID-19 and the ongoing work to protect public health. Government of Alberta; 2020 May 11. Available: www.alberta.ca/release.cfm?xID=713293A50B3C8-ED31-6A0E-B72A0FE682E3F1EC (accessed 2020 Sept. 10).

6. What you need to know about COVID-19 in Alberta on Saturday, May 16. CBC [Calgary] 2020 May 16. Available: www.cbc.ca/news/canada/calgary/what -you-need-to-know-alberta-may-16-1.5573241 (accessed 2020 Sept. 10).

7. Lan F-Y, Wei C-F, Hsu Y-T, et al. Work-related COVID-19 transmission in six Asian countries/areas: a follow-up study. PLoS One 2020;15:e0233588.

8. Park S, Kim Y, Yi S, et al. Coronavirus disease outbreak in call center, South Korea. Emerg Infect Dis 2020;26:1666-70.

9. Colbourne T. COVID-19: extending or relaxing distancing control measures. Lancet 2020;5:e236-7.

10. Tuite A, Fisman DM, Greer AL. Mathematical modelling of COVID-19 transmission and mitigation strategies in the population of Ontario, Canada. CMAJ 2020;192:E497-E505.

11. Flaxman S, Mishra S, Gandy A, et al. Estimating the number of infections and the impact of nonpharmaceutical interventions on COVID-19 in 11 European countries. London (UK): Imperial College London; 2020 Mar. 30. doi: https:// doi.org/10.25561/77731

12. Keeling MJ, Hollingsworth TD, Read JM. The efficacy of contact tracing for the containment of the 2019 novel coronavirus (COVID-19). medRxiv 2020 Feb. 17. doi: https://doi.org/10.1101/2020.02.14.20023036

13. Bi O, Wu Y, Mei S, et al. Epidemiology and transmission of COVID-19 in Shenzhen China: analysis of 391 cases and 1286 of their close contacts medRxiv 2020 Mar. 27. doi: https://doi.org/10.1101/2020.03.03.20028423

14. Anderson RM, Heesterbeek $\mathrm{H}$, Klinkenberg D, et al. How will country-based mitigation measures influence the course of the COVID 19 epidemic. Lancet 2020;395:931-4.

15. AHS Scientific Advisory Group. Effectiveness of screening programs for reducing the spread of COVID-19 in healthcare settings. In: COVID-19 Scientific Advisory Group rapid evidence report. Alberta Health Services; 2020 June 12. Available: www.albertahealthservices.ca/assets/info/ppih/if-ppih-covid-19-sag-effectiveness -of-workplace-screening-programs-rapid-review.pdf (accessed 2020 Sept. 10).

16. Overview of testing for SARS-CoV-2 (COVID-19). Atlanta: Centers for Disease Control and Prevention; updated 2020 Sept. 18. Available: www.cdc.gov/ coronavirus/2019-ncov/hcp/testing-overview.html (accessed 2020 Sept. 10). 
Competing interests: Isaac Bogoch reports that he has consulted for BlueDot, a social benefit corporation that tracks the spread of emerging infectious diseases. Jeffrey Shaw, Tyler Williamson and Hayley Wickenheiser report having created Pandemic Solutions, which helps companies implement this idea in their workforce; the idea was conceived and shared with colleagues and policy-makers well before the company was created. No other competing interests were declared.

This article has been peer reviewed.

Affiliations: Department of Critical Care Medicine (Shaw), Cumming School of Medicine,
University of Calgary, Calgary, Alta.; Department of Mathematics and Statistics (Day), Department of Biology, Queen's University, Kingston, Ont.; Customer Strategy \& Aircraft Delivery Performance (Malik), and Operational Industrialization, Footprint \& Central Planning (Barber), Bombardier Aviation, Montréal, Que.; Cumming School of Medicine (Wickenheiser), University of Calgary, Calgary, Alta.; Dalla Lana School of Public Health (Fisman), University of Toronto, Toronto, Ont.; Divisions of General Internal Medicine and Infectious Diseases (Bogoch), University Health Network, Toronto General Hospital, Toronto, Ont.; Department of Pediatrics (Brownstein), Harvard Medical
School, Boston Children's Hospital, Boston, Mass.; Department of Community Health Sciences (Williamson), Cumming School of Medicine, University of Calgary, Calgary, Alta.

Contributors: All of the authors contributed to the conception and design of the work, and the acquisition, analysis, and interpretation of data. All of the authors drafted the manuscript, revised it critically for important intellectual content, gave final approval of the version to be published and agreed to be accountable for all aspects of the work.

Correspondence to: Jeffrey Shaw, jashaw@ucalgary.ca 